\title{
Quality by Design (QbD): An Emerging Trend in Improving Quality \& Development of Pharmaceuticals
}

\author{
Mr. Shrikant M. Mohurle ${ }^{1 *}$, Ms. Dr. Alpana J. Asnani ${ }^{1}$, Dr. Dinesh R. Chaple ${ }^{1}$, Mr. Jacob Kurian ${ }^{2}$, Mr. Abhinav G. Bais ${ }^{1}$
}

${ }^{1}$ Priyadarshini J.L.College of Pharmacy, Electronics Zone Building, MIDC, Hingna Road Nagpur, Maharashtra 440016, India

${ }^{2}$ Priyadarshini J.L.Chaturvedi College of Pharmacy, (Diploma), 846, New Nandanvan, Nagpur Maharashtra 440009, India

\begin{abstract}
DOI: $10.36348 /$ sjmps.2019.v05i12.019 $\quad$ | Received: 20.12.2019| Accepted: 27.12 .2019 | Published: 30.12 .2019
*Corresponding author: Mr. Shrikant M. Mohurle
\end{abstract}

\section{Abstract}

As pharmaceutical industries now a days concerns with the safety and continuously enhance the quality of the drug products. The development of pharmaceutical industries is based on the innovation of the product as well as the manufacturing process by keeping quality in the mind. In earlier times, the development of pharmaceutical products shows the failure in the quality and hence alters the therapeutic effect of the product. Quality by test (QbT) was the only way to maintain the quality of the drug product before the FDA launches the current Good Manufacturing Practices (cGMP), which was an approach without understanding the processes. So FDA decided to applied the several Design of Experiments (DoE) in the pharmaceutical fields. QbD (Quality by design) was one of the design experiment approved by the FDA to maintain the quality of the drug products before reaching to the market. In pharmaceutical industry, QbD brings cost-efficiency and simplicity of manufacturing process into reality. QbD is a systematic risk-based, proactive approach to pharmaceutical development that begins with predefined objectives and emphasizes product and process understanding and process control based on sound science and quality risk management. The main aim of this review is to discuss the concept of pharmaceutical Quality by Design and describe how it can be helpful to ensure pharmaceutical quality \& drug development.

Keywords: Quality by design (QbD), current Good Manufacturing Practices (cGMP), Design of Experiments (DoE), quality, FDA, pharmaceutical products.

Copyright @ 2019: This is an open-access article distributed under the terms of the Creative Commons Attribution license which permits unrestricted use, distribution, and reproduction in any medium for non-commercial use (NonCommercial, or CC-BY-NC) provided the original author and source are credited.

\section{INTRODUCTION}

Quality by design (QbD) is a concept first invented by the quality scientist Dr. Joseph M. Juran [1]. Dr. Juran believed that quality should be designed into a product, and that most quality crises and problems relate to the way in which a product was designed in the first place. Woodcock defined a highquality drug product as a product that should be free from contamination and reliably delivering the therapeutic response promised in the label to the consumer [2]. The US Food and Drug Administration (FDA) encourages risk-based approaches and the adoption of $\mathrm{QbD}$ principles in drug product development, manufacturing, and regulation. FDA's emphasis on QbD began with the recognition that increased testing does not necessarily improve product quality. Quality must be built into the product.

The concept of QbD was mentioned in the ICH Q8 guidance, which states that "quality can not be tested into products, i.e., quality should be built in by design".

International conference on hominization (ICH) Q8 (R1) guideline defines QbD as "a systematic approach to development that begins with predefined objectives and emphasizes product and process understanding and process control, based on sound science and quality risk management" [3].

\section{DEFINITION: Quality by Design}

$\mathrm{QbD}$ is a systematic approach that helps in the development of the pharmaceutical product by improving the quality. It begins with the predefined objectives and process understanding and process control, based on sound science and quality risk management [4].

\section{Quality}


The features or characteristics of the product that bear on its ability to stated and implied needs [5].
Design

This refers to the plan or sequence for the construction of an object [5].

Table-1: List of regulatory guidances or other QbD related activities

\begin{tabular}{|c|c|c|}
\hline Agency & Guidelines/Activities & Month Year \\
\hline USFDA & $\begin{array}{l}\text { Pharmaceutical cGMP for the } 21^{\text {st }} \text { Century - A Risk Based Approach: Second Progress } \\
\text { Report and Implementation Plan [6]. }\end{array}$ & Sep 2003 \\
\hline USFDA & $\begin{array}{l}\text { Guidance for Industry: PAT - A Framework for Innovative Pharmaceutical Development, } \\
\text { Manufacturing, and Quality Assurance [7]. }\end{array}$ & Sep 2004 \\
\hline USFDA & Pharmaceutical cGMP for the $21^{\text {st }}$ Century - A Risk-Based Approach:Final Report [8]. & Sep 2004 \\
\hline EMA & $\begin{array}{l}\text { The European Medicines AgencyRoad Map to 2010: Preparing theGround for the Future } \\
\text { [9]. }\end{array}$ & March 2005 \\
\hline $\mathrm{ICH}$ & Pharmaceutical Development (Q8) [10] & Nov 2005 \\
\hline $\mathrm{ICH}$ & Quality Risk Management (Q9) [11] & Nov 2005 \\
\hline $\mathrm{ICH}$ & Pharmaceutical Quality System(Q10) [12] & June 2008 \\
\hline $\mathrm{ICH}$ & Pharmaceutical Development(Q8(R2)) [6] & Aug 2009 \\
\hline WHO & Quality Risk Management [13] & Aug 2010 \\
\hline EMA & Road map to $2015[14]$ & Dec 2010 \\
\hline USFDA & Guidance for Industry: Process Validation: General Principles and Practices [15] & Jan 2011 \\
\hline EMAUSFDA & EMA-FDA pilot program for parallelassessment of Quality by Designapplications [16] & March 2011 \\
\hline $\mathrm{ICH}$ & ICH-Endorsed Guide for ICH Q8/Q9/Q10 Implementation [17] & Dec 2011 \\
\hline EMA & ICH Quality IWG Points to consider for ICH Q8/Q9/Q10 guidelines [18] & Feb 2012 \\
\hline EMA & Guideline on Real Time Release Testing (formerly Guideline on Parametric Release) [19] & March 2012 \\
\hline EMA & Guideline on Process Validation(draft) [20] & March 2012 \\
\hline USFDA & Quality by Design for ANDAs: An Example for Immediate-Release Dosage Forms [21] & April 2012 \\
\hline $\mathrm{ICH}$ & $\begin{array}{l}\text { Development and Manufacture of Drug Substances } \\
\text { Biotechnological/Biological entities) } \\
(\mathrm{Q} 11)[22]\end{array}$ & May 2012 \\
\hline EMA-USFDA & $\begin{array}{l}\text { EMA-FDA pilot program for parallel assessment of Quality-by-Design applications: } \\
\text { lessons learnt and Q\&A resulting from the first parallel Assessment [23] }\end{array}$ & Aug 2013 \\
\hline EMA & $\begin{array}{l}\text { Guideline on process validation for } \\
\text { finished products - information and } \\
\text { data to be provided in regulatory } \\
\text { submissions [24] }\end{array}$ & Feb 2014 \\
\hline
\end{tabular}

\section{Characteristics of QbD [25, 26]}

- An approach for development of efficient drug product.

- It is a dynamic and systematic process

- This approach relies on the concept that Quality can be built in as a continuum.

- It is applicable to both drug Product and Drug Substance development (chemicals biologics)

- It is also applicable to analytical methods.

- Can be used at any time in the life cycle of the Drug.

- Always encouraged by Regulators.

\section{Objectives of Pharmaceutical Quality by Design (QbD) [27]}

Pharmaceutical QbD is a systematic approach to development that begins with the predefined objectives and process understanding and process control, based on sound science and quality risk management [4].

The goals of pharmaceutical QbD may include the following:
- To achieve meaningful product quality specifications that is based on clinical activities.

- To enhance process capability and reduce product variability and defects by enhancing product and process design, understanding, and control.

- To increase pharmaceutical product development and manufacturing efficiencies.

- To enhance root cause analysis and post approval change management.

\section{Advantages of QbD [28]}

- It involves both the patient safety as well as efficacy of the product.

- The scientific understanding of the process involved in the manufacturing of the product can be done easily.

- It includes both product design as well as process development.

- The science based risk assessment can be carried out by this approach.

- It is a robust process. 
- Critical quality attributes are identified and their effect on final quality of product is analysed.

\section{Quality by Design Process}

Quality by Design is a scientific risk based holistic and proactive approach to pharmaceutical development by improving its quality. It involves the designing and planning of a drug product and process before actual experiment.

Overview of $\mathrm{QbD}$ process is explained in Figure-1.

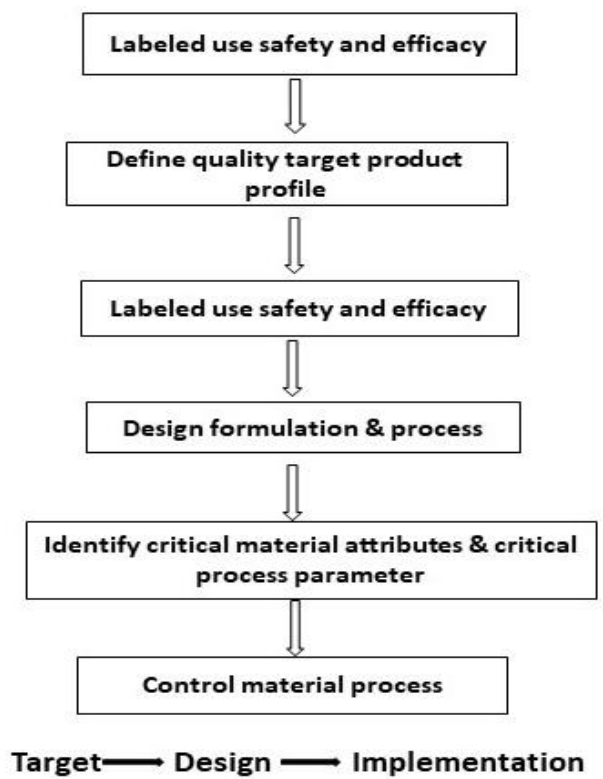

Fig-1: Overview of $\mathrm{QbD}$ process

Briefly a QbD development process includes stages as described below:

- A target product profile describes the use, safety and efficacy of the product.

- Defining a target product quality profile is used by formulators and process engineers as a quantitative surrogate for aspects of clinical safety and efficacy during product development.

- Drawing together relevant prior knowledge about the drug substance, potential excipients and process operations into a knowledge space. Use a risk assessment to prioritize knowledge gaps for further investigation.

- Designing a formulation and identify the critical material attributes of the final product that must be controlled to meet the target product quality profile.

- Designing a manufacturing process to produce a final product having critical material attributes.
- Identifying the critical process parameters and raw material attributes that must be controlled to achieve critical material attributes of the final product. Use of risk assessment to prioritize process parameters and material attributes for experimental verification. Combine prior knowledge with experiments to establish a design space or other representation of process understanding.

- Establishing a control strategy for the entire process that may include input material controls, process controls. The control strategy should encompass expected changes in scale and can be guided by a risk assessment.

- Continuous monitoring and updating the process to assure consistent quality.

\section{ELEMENTS OF PHARMACEUTICAL QUALITY BY DESIGN}

As $\mathrm{ICH}$ guidelines defines the $\mathrm{QbD}$ for the pharmaceutical development. ICH Q8 defines the various elements of quality by design. These in combination with the enablers form the fundamental basis for the QbD approach to development. It involves the following key elements during pharmaceutical development

- Define the Quality Target Product Profile

- Identify the Quality Attributes

- Perform a Risk (Assessment) Analysis

- Determine the Critical Quality Attributes and Critical Process Parameters

- Determine the Design Space

- Identify a Control Strategy

\section{Identifying a Quality Target Product Profile (QTPP)}

FDA published a recent guidance defining a target product profile: The target product profile (TPP) has been defined as a"prospective and dynamic summary of the quality characteristics of a drug product that ideally will be achieved to ensure that the desired quality, and thus the safety and efficacy, of a drug product is realized" [29].

This includes dosage form and route of administration, dosage form strength(s), therapeutic moiety release or delivery and pharmacokinetic characteristics (e.g., dissolution and aerodynamic performance) appropriate to the drug product dosage form being developed and drug product-quality criteria (e.g., sterility and purity) appropriate for the intended marketed product [30].

The concept of TPP in this form and its application is novel in the QbD paradigm. The Target Product Quality Profile (TPQP) is a term that is a natural extension of TPP for product quality. It is the quality characteristics that the drug product should possess in order to reproducibly deliver the therapeutic benefit promised in the label. The TPQP guides 
formulation scientists to establish formulation strategies and keep formulation efforts focused and efficient. TPQP is related to identity, assay, dosage form, purity, stability in the label [31].

Quality target product profile (QTPP) Includes, but not limited to:

- Dosage form
- Route of administration

- Strength

- Release or Delivery of the drug

- Pharmacokinetic characteristics dissolution, aerodynamic performance

- Drug product quality characteristics for intended use e.g., sterility, purity.

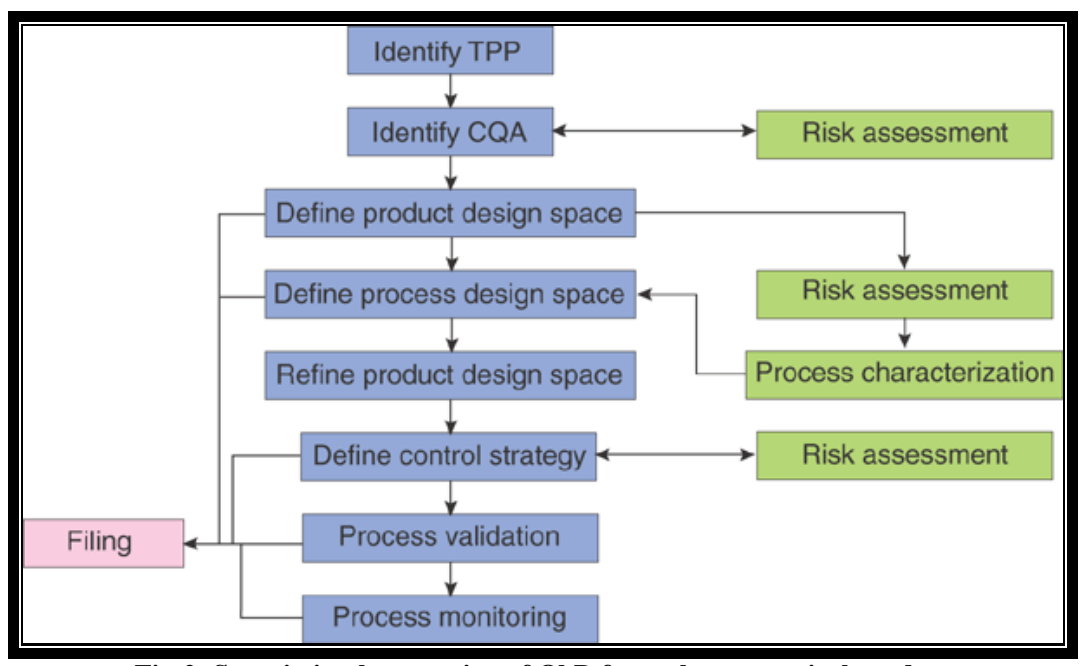

Fig-2: Steps in implementation of QbD for a pharmaceutical product

\section{Critical Quality Attributes (CQA)}

Once QTPP has been identified, the next step is to identify the relevant CQAs. A CQA is defined as "A physical, chemical, biological or microbiological property or characteristic that should be within an appropriate limit, range, or distribution to ensure the desired product quality".
The CQA element is very important and it is associated with the raw materials, intermediates as well as the drug products.

It is studied that CQA is a subset of QTTP that changes with the change in the different formulation variables [32, 33]. As per the ICH guidelines the identification of CQAs can be done through the risk assessment.

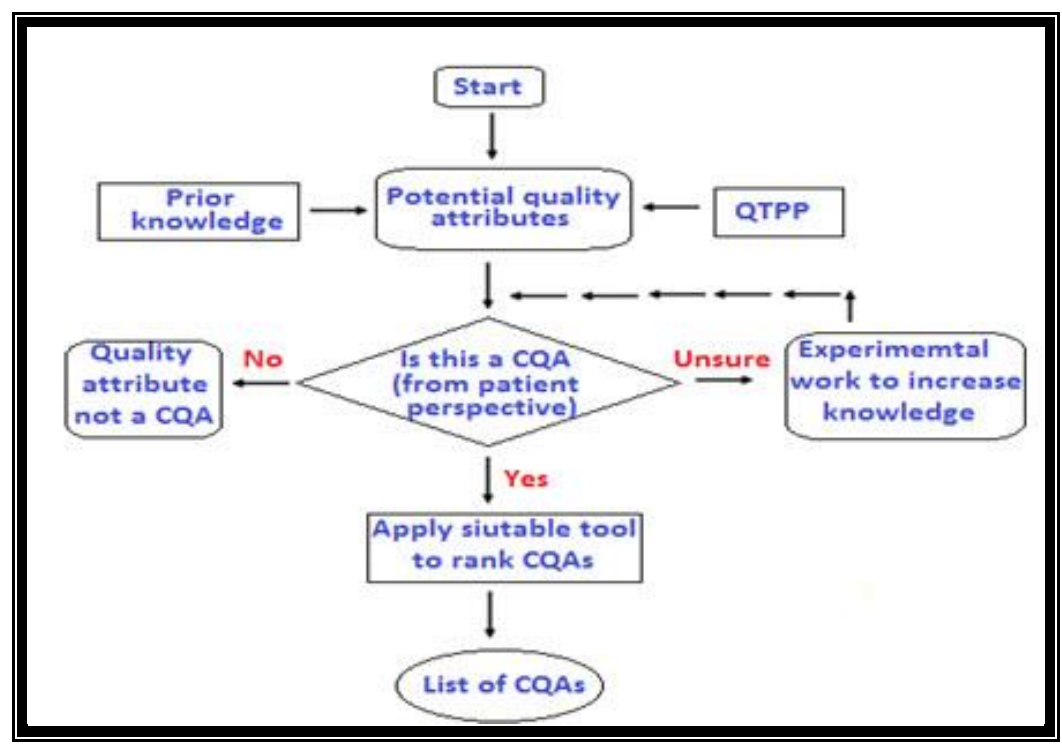

Fig-3: Decision Tree to Decide CQAs

Table-2: Typical CQAs for drug substance and drug products

\begin{tabular}{|l|l|}
\hline $\begin{array}{l}\text { For Drug Substance } \\
\text { (chemical) }\end{array}$ & $\begin{array}{l}\text { For Drug product } \\
\text { (tablet) }\end{array}$ \\
\hline
\end{tabular}

For Drug Substance (chemical) (tablet) 
Shrikant M. Mohurle et al; Saudi J Med Pharm Sci, Dec., 2019; 5(12): 1132-1138

\begin{tabular}{|l|l|}
\hline Appearance & Appearance \\
\hline Particle size & Identification \\
\hline Morphic forms & Hardness \\
\hline Water content & Uniformity of dosage \\
\hline Residual solvents & Physical form \\
\hline Organic impurities & Dissolution \\
\hline Inorganic impurities & Degradation products \\
\hline Heavy metals & Water content \\
\hline Assay & Microbiological limits \\
\hline
\end{tabular}

\section{QUALITY RISK MANAGEMENT (QRM)}

It is very important to decide the manufactures for study that to be conduct. It helps in linking the quality attributes as well as process parameters to CQAs. The evaluation of the quality risk should be based on the both scientific knowledge as well as therapeutic benefit to the patient [34].

The ICH Q9 guidelines provide a quality risk management which provides a structure to initiate the risk process.

\section{Several tools are involved in the risk assessment:}

- Failure mode effects analysis (FMEA)

- Failure Mode, Effects and Criticality Analysis (FMECA)

- $\quad$ Fault tree analysis (FTA)

- Hazard analysis and critical control points (HACCP)

\section{DETERMINATION OF CRITICAL PROCESS PARAMETERS}

\section{What is a Process Parameter?}

Critical process parameters (CPP) is defined as any measurable input such as input material attribute or output such as output material attribute of a process step that should be controlled to achieve the desired product quality as well as process uniformity [35].

For example, a material attribute, such as moisture content, should have the same target value in the pilot and commercial processes. An operating parameter, such as air flow rate, would be expected to change as the process scale changes.

For a given unit operation, there are four categories of parameters and attributes

- Input material attributes

- Output material attributes

- Input operating parameters

- Output process state conditions.

Table-3: Different critical process parameters during tableting

\begin{tabular}{|l|l|}
\hline $\begin{array}{l}\text { Operations } \\
\text { during tableting }\end{array}$ & Critical Process Parameters \\
\hline Wet granulation & Mixing time \\
\hline
\end{tabular}

\begin{tabular}{|c|c|}
\hline & $\begin{array}{l}\text { Impeller speed } \\
\text { Binder fluid addition rate \& time } \\
\text { Method of binder addition } \\
\text { Temperature }\end{array}$ \\
\hline Drying & $\begin{array}{l}\text { Drying time } \\
\text { Inlet air flow } \\
\text { Exhaust air temperature \& flow }\end{array}$ \\
\hline Milling & $\begin{array}{l}\text { Milling speed } \\
\text { Screen size } \\
\text { Feeding rate }\end{array}$ \\
\hline Mixing & $\begin{array}{l}\text { Mixer type } \\
\text { Mixing time } \\
\text { Order of addition }\end{array}$ \\
\hline Compression & $\begin{array}{l}\text { Pre compression force } \\
\text { Main compression force } \\
\text { Dwell time } \\
\text { Hopper design } \\
\text { Punch penetration depth } \\
\text { Roller type }\end{array}$ \\
\hline Coating & $\begin{array}{l}\text { Inlet air flow } \\
\text { Time } \\
\text { Temperature } \\
\text { Spray pattern \& rate }\end{array}$ \\
\hline
\end{tabular}

\section{DESIGN SPACE}

The ICH Q8 (R2) defines the design space as to ensure the quality of the product. The design space is defined as the multidimensional combination and interaction of the input variables and process parameters to provide assurance of the quality [36].

This definition arises from early ICH Q8 drafts where design space was defined as "the established range of process parameters that has been demonstrated to provide assurance of quality".

Methods for determining design space included: one variable at a time experiments, statistically designed experiments, and modeling approaches. Methods for presenting design space included graphs (surface-response curves and contour plots), linear combination of parameter ranges, equations, and models. Alternatively, the design space can be explained mathematically through equations describing relationships between parameters for successful operation [37-39].

\section{CONTROL STRATEGY}

ICH Q10 characterizes a control technique as "an arranged arrangement of controls got from current item and procedure understanding that guarantees procedure execution and item quality. The controls can incorporate parameters and ascribes identified with medication substance and medication item materials and segments, office and hardware working conditions, in procedure controls, completed item determinations and the related techniques and recurrence of observing and control." A control methodology typically incorporate information material controls, process controls and observing, structure space around individual or numerous unit activities, as well as 
definite item determinations used to guarantee reliable quality $[40,41]$.

A QbD based control strategy for blending process is shown in Fig-4.

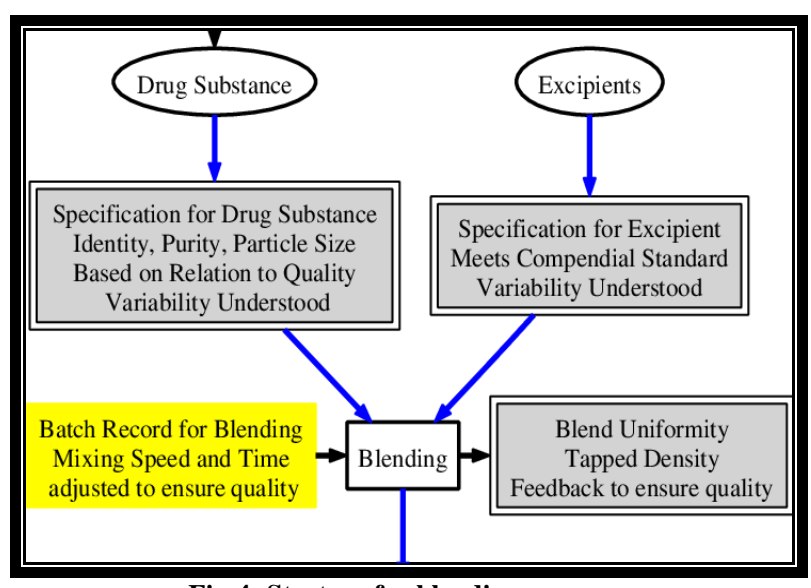

Fig-4: Strategy for blending process

\section{CONCLUSION}

$\mathrm{QbD}$ is progressively turning into a significant and broadly utilized method in pharmaceutical item improvement. While QbD is best when it is utilized at an item/process configuration level, it ought to like wise be cultivated in the assembling and quality confirmation conditions. Executing QbD idea in item advancement give quality meds to patients, creation upgrades to manufacturers with essentially decreased cluster disappointments and medication administrative bodies will have more noteworthy trust in the powerful nature of items. This methodology permits the foundation of needs and adaptable limits all the while. Accordingly $\mathrm{QbD}$ is turning into a promising logical apparatus in quality affirmation in pharmaceutical industry.

This paper explains the utilization of QbD including:

- Accentuation on the significance of the Target Product Quality Profile in articulating a quantitative execution focus for QbD.

- Distinguishing proof of basic material properties that give a robotic connection of the item quality to the assembling procedure.

- The job of the control technique as the component for steady usage of QbD components into training.

- An effective way to a plan space through the recognizable proof of non-interfacing process factors and their avoidance from formal test plans.

\section{REFERENCES}

1. Juran, J. M. (1992). Juran on quality by design: the new steps for planning quality into goods and services. New York: The Free Press.

2. Woodcock, J. (2004). The concept of pharmaceutical quality. Am Pharm Rev, 1-3.
3. International Conference on Harmonization (ICH). (2009). Tripartite guidelines,' ICH Q8 (R2): Pharmaceutical Development', London.

4. Watts, C. (2004, December). PAT-A framework for Innovative Pharmaceutical Development Manufacturing and Quality Assurance. In FDA/RPSGB Guidance Workshop.

5. Quality by Design (QbD) - Principles " $29^{\text {th }}$ jan, 2013, Saurastra University, Rajkot, By Dr C. V. S. Subrahmanyam, Principal, Gokaraju Rangaraju College of Pharmacy, Hyderabad.

6. USFDA. (2003). Pharmaceutical cGMP for the 21st Century - A Risk-Based Approach: Second Progress Report and Implementation Plan Introduction, Food and Drug Administration, Rockville, MD.

7. USFDA. (2004). Guidance for Industry: PAT - A Framework for Innovative Pharmaceutical Development, Manufacturing, and Quality Assurance, Food and Drug Administration, Rockville, MD.

8. USFDA. (2004). Pharmaceutical cGMP for the 21st Century - A Risk-Based Approach: FinalReport, Food and Drug Administration, Rockville, MD.

9. EMA, http://www.emea.europa.eu/docs/en_GB/documen t_library/Report/2009/10/WC500004903.pdf

10. ICH. (2005). Pharmaceutical Development Q8, International Conference on Harmonisation, IFPMA, Geneva (Switzerland).

11. ICH. (2005). Quality Risk Management Q9, International Conference on Harmonisation, IFPMA, Geneva (Switzerland).

12. ICH. (2008). Pharmaceutical Quality System Q10, International Conference on Harmonisation, IFPMA, Geneva (Switzerland).

13. WHO. (2010). Guideline on Quality Risk Management, World Health Organization, Geneva (Switzerland), 2010.

14. EMA-USFDA, http://www.ema.europa.eu/docs/en_GB/document _library/ Report/2011/01/WC500101373.pdf

15. USFDA. (2011). Guidance for Industry: Process Validation: General Principles and Practices, Food and Drug Administration, Rockville, MD, 2011.

16. EMA-USFDA, http://www.ema.europa.eu/docs/en_GB/document _library/Other/2011/03/WC500103621.pdf

17. $\mathrm{ICH}$,

http://www.ich.org/fileadmin/Public_Web_Site/IC H_Products/Guidelines/Quality/Q8_9_10_QAs/Pt C/Quality_IWG_PtCR2_6dec2011.pdf

18. EMA,

http://www.ema.europa.eu/docs/en_GB/document _library/Scientific_guideline/2012/03/WC500123 518.pdf

19. EMA, http://www.ema.europa.eu/docs/en_GB/document 
_library/Scientific_guideline/2012/04/WC500125 401.pdf

20. EMA

http://www.ema.europa.eu/docs/en_GB/document _library/Scientific_guideline/2012/04/WC500125 399.pdf.

21. USFDA,

http://www.fda.gov/downloads/Drugs/Developme ntApprovalProcess/How Drugs are Developed and Approved/Approval

Applications/AbbreviatedNew Drug Application ANDA Generics/UCM304305.pdf

22. ICH. (2012). Development and Manufacture of Drug Substances (Chemical Entitiesand Biotechnological/Biological Entities) Q11, International Conference on Harmonisation, Geneva, (Switzerland).

23. EMA-USFDA, http://www.ema.europa.eu/docs/en_GB/document _library/Other/2013/08/WC500148215.pdf

24. EMA,

http://www.ema.europa.eu/docs/en_GB/document _library/Scientific_guideline/2014/02/WC500162 136.pdf.

25. Anuj, G., \& Fuloria, N. K. (2012). Short review on Quality by design: A new Era of Pharmaceutical drug development. International Journal of Drug Development and Research, 4(3):19-26.

26. Elliott, P., Billingham, S., Bi, J., \& Zhang, H. (2013). Quality by design for biopharmaceuticals: a historical review and guide for implementation. Pharmaceutical bioprocessing, 1(1), 105-122.

27. Nadpara, N. P., Thumar, R. V., Kalola, V. N., \& Patel, P. B. (2012). Quality by design (QBD): A complete review. Int J Pharm Sci Rev Res, 17(2), 20-28.

28. ICH. (2007). Draft consensus guideline: pharmaceutical development annex to Q8. Available at:, MEDIA4349.pdf (accessed 11/21/2007).

29. Delasko, J., Cocchetto, D. M., \& Burke, L. B. (2005). Target product profile: beginning drug development with the end in mind. Update.

30. Food and Drug Administration CDER. (2007). Draft Guidance for Industry and Review Staff: Target Product Profile- A Strategic Development Tool (March 2007).

31. Food and Drug Administration Office of Generic Drugs. (2006). Model Quality Overall Summary for IR Product, http:// www.fda.gov/ cder/ ogd/OGD_Model-QoS_IR_Product.pdf (Accessed March 31, 2006).

32. Patil, A. S., \& Pethe, A. M. (2013). Quality by Design (QbD): A new concept for development of quality pharmaceuticals. International journal of pharmaceutical quality assurance, 4(2), 13-19.

33. Nagar, M., Panwar, K. S., Chopra, V. S., Bala, I., \& Trivedi, P. (2010). Quality by design: A systematic approach to pharmaceutical development. Der Pharmacia Lettre,2(2), 111130.

34. Bhattacharya, J. (2015). Quality Risk Management-Understanding and control the risk in pharmaceutical manufacturing industry. International Journal of Pharmaceutical Science Invention, 4(1), 29-41.

35. Chowdary, K. P., Shankar, K. R., \& Kumar, P. S. (2014). Recent research on QbD approach in formulation development: A review. International Journal of Chemical Science and Technology, 4(1), 282-292.

36. USFDA. (2006). Guidance for industry: Q8 pharmaceutical Development, US Department of Health and Human Service, FDA Rockville, MD.

37. Wu, H., White, M., \& Khan, M. A. (2011). Quality-by-Design (QbD): An integrated process analytical technology (PAT) approach for a dynamic pharmaceutical co-precipitation process characterization and process design space development. International journal of pharmaceutics, 405(1-2), 63-78.

38. Altan, S., Bergum, J., Pfahler, L., Senderak, E., Sethuraman, S., \& Vukovinsky, K. E. (2010). Statistical considerations in design space development (Part I of III). Pharmaceutical Technology, 34(7), 66-70.

39. Altan, S., Bergum, J., Pfahler, L., Senderak, E., Sethuraman, S., \& Vukovinsky, K. E. (2010). Statistical Considerations in Design Space Development (Part II of III). Pharmaceutical Technology, 34(8), 52-60.

40. Trivedi, B. (2012). Quality by desing (QbD) in pharmaceuticals. Int J Pharm Pharm Sci, 4:17-29.

41. Jain, S. (2014). Quality by design (QBD): a comprehensive understanding of implementation and challenges in pharmaceuticals development. Int. J. Pharm. Pharm. Sci, 6, 29-35. 